\title{
A Study of Job Attributes, Strategic Behavior and Governance of University Faculty in China
}

\author{
Liu Pingping \\ School of Foreign Language \\ Southwest Petroleum University \\ Chengdu, China \\ 184418477@qq.com
}

\begin{abstract}
In recent years, the constantly occurring phenomenon that behavior of university faculty members departs from their roles, such as academic misconduct and negligence in undergraduate teaching, directly influences the social reputation and healthy development of universities in China. Within this context, this study examines the two job attributes of university faculty, namely teaching and research, which are brought into the framework of administrative governance, and analyzes the institutional causes of the behavior mentioned above. The study shows that in Chinese colleges and universities, teaching and research are in contradiction with administrative governance. As for the lack of self-discipline mechanism, faculty members' academic misconduct and negligence in undergraduate teaching are their rational individual behavior. Thus recommendations for governing their rational behavior, particularly through innovating in governance model and reinforcing self-discipline mechanism, are provided.
\end{abstract}

Keywords-university faculty, behavior alienation, university governance, standardized model

\section{INTRODUCTION}

Faculty members in university are intellectuals as well as producers of intellectuals [1]. As the important behavioral subjects of social function of higher education, faculty members' behavior of teaching and research are closely related to the quality and sustainable development of higher education. Based on their significant roles in higher education system, measures to protect the construction of teaching staff in universities and colleges are explicitly proposed in Outline of China's National Medium- and Long-term Program of Education Reform and Development. On the 30th National Teachers' Day, President Xi Jinping reemphasized the vital function that teachers served in talent-nurturing and national modernization and raised new requests for construction of teaching staff.

For the past few years, academic dishonesty, plagiarism and date frauds in university teaching staff have been constantly reported in various media, as well as undesirable phenomena that they don't settle down to undergraduate teaching, and even refuse to give lectures to undergraduates, giving rise to publics' doubts about their behavior. In this study, the undesirable behavior of university faculty members which departs from their expected social roles, like academic misconduct and irresponsibility in teaching is generally defined as strategic behavior for convenience. The strategic behavior of faculty members poses a negative effect on the social reputation of faculty in the university, and tarnishes faculty's image in students' mind, making their teaching less appealing, so as to directly influence the teaching effect and the quality of talent nurturing. Although the strategic behavior is in a minority of cases, its impact cannot be ignored. The essence of it, under the certain administrative governance environment, is the rational response from faculty members as rational economic men, social being, academic people towards existing institutional arrangement of teaching and research in universities and colleges.

However, from the perspective of social welfare, such rational behavior of faculty members is actually escaping their social responsibilities that they should take, which can be defined as a phenomenon of behavior alienation. A study suggests that faculty members' strategic behavior, which depends on environmental factor, is the direct reaction to the unhealthy social climate in universities and colleges, and also the outcome caused by faculty members interacting with social context [2]. As for recognizing and solving problems, it makes little sense to attribute faculty members' strategic behavior to social environmental factors, in spite of a certain relationship between them, as it is basically a type of environmental determinism, and meanwhile cannot explain faculty members' different behavior in the same environment. In fact, to explore the internal logical relationship between faculty members' job attributes, strategic behavior and management model is the basis of behavior governance, which is also beneficial to discovering the essence of this phenomenon and conducive to the construction and development of teaching staff in China's universities and colleges.

\section{ANALYSIS ON BASIC ATtRIBUTES OF FACUlty MEMBERS' RESEARCH AND TEACHING}

The university, as a special social organization and academic community, is the unity of abstract targets and concrete goals. Its function, role and social value are determined by its target positioning. Generally speaking, the social value of university is embodied in four functions, namely nurturing the talent, generating knowledge, serving the society and inheriting \& passing on culture [3]. Faculty plays a vital role in the process of realizing the social functions of university, as Mr. Mei Yiqi said, "it is the great masters, not 
huge buildings that characterize a university". Faculty members are the major employees who are undertaking teaching and academic activities, whose work behavior occurs in the process of nurturing the talent, generating knowledge, serving the society and inheriting \& passing on culture, which are subject to two attributes ---- teaching and research [4].

University Differentiation was caused by social needs, resources endowment and development orientation, thus different forms of organization appeared, including researchintensive university, teaching-intensive university and teaching-research mixed university. They bear their social roles in accord with the target positioning in the process of realizing university's function [5]. Although faculty members' emphases in work are different in different types of universities, teaching and research are implied in faculty members' job responsibility and expectation of social roles throughout their whole career. If their job duties and roles are strictly distinguished in teaching and research, the two interconnected work systems, the result would be the different proportions of research and teaching activity to institutional work content in different types of universities. That is to say, deviating from research and teaching, which are the essential work of faculty would keep their roles away from social expectation, and accordingly give rise to constant population alienation in biological category, followed by the appearance of corruption because they couldn't receive the environmental recognition, and finally result in the degeneration of the whole ecosystem. The basic functions of university are realized and accomplished by the two scientifically organizing activities -teaching and research. Both of them are a process of input and output with their own regularities, which directly reflect faculty members' job attributes of teaching and research.

\section{A. Analysis on Faculty Members' Job Attribute of Research}

Despite the different processes and forms, research happened in certain time and space, with researchers as its crucial element of input, is a process of knowledge accumulation and innovation, characterized by autonomy, invisibility, innovation, uncertainty and cooperation.

(1) Autonomy and Invisibility. Happened in certain time and space, the process of research is comparatively independent and impossible to observe. Its attribute offers a challenge to the effectiveness of traditional management model. Suppose that the research is managed by the way of factory management: research of all the researchers is managed by a 'foreman' with administrative authority, employed by the 'investor' or 'boss', then the management would be confronted with two problems, namely technical incomprehensibility and information asymmetry.

(2) Innovation. As the social value of research, innovation itself features non-standardized and non-programmed productive process. If Taylor's mode of factory production is adopted, research is scheduled by the plans, examined and evaluated by planning time and quantity of the output, so as to judge its efficiency and the superiority or inferiority of researchers. This way not only violates the regularity of research, but also strangles its innovation.
(3) Uncertainty. The uncertainty of research, found in its process and result of output, presents a certain risk. Based on continual 'trial and error', the success of research is accidental. So the failure should be allowed in research for its risk and relationship with success. If possibility of failure and probability of success, both are coexisted in one job, then the performance management of research encounters another challenge, which is how to choose the job standards.

(4) Cooperation. Research can be done by a single person, and also a team. But along with the depth of research, the form of team-based organization has become normal. Teamwork can be fulfilled within the organization and cross-organization. It is the high flexibility of its organization form and ambiguity of organization boundary that determine its requirement for academic authority and association power to be rational and valid.

\section{B. Analysis on Faculty Members' Job Attribute of Teaching}

Teaching job, as the basic form to nurture talents in universities and colleges, is mainly fulfilled by faculty members. Throughout the process of knowledge creation and service, the teaching activity of faculty is typically characterized by interactivity, incomparability and covertness.

(1) Interactivity. University teaching is participated and completed by faculty members and students in a certain organizational form. Its outcome is determined by the pattern and degree of the interaction between teaching and learning. That is to say, the instructional effectiveness depends on both objective factors like the content and way of teaching activity, and subjective factors, such as the teacher-student behavioral motivation and their perception of social relations between each other, which is relevant to teachers' general condition, level of effort and working state, as well as students' interest of study, motivation, opportunity and degree of participation.

(2) Incomparability. The teaching activity of faculty members varies in teaching object, content and organizational depending on different disciplines and majors. This poses a dilemma of equity and efficiency in the performance evaluation of faculty inside the organization. From the perspective of efficiency, the work performance of faculty members from different majors and disciplines should be evaluated against the same criterion. Apparently, the standardized evaluation denies the fact that their performance is influenced by the differences of disciplines, and then inevitably causes a sense of unfairness to faculty members. From the perspective of equity, the work performance of faculty members should be evaluated against the different criteria in accordance with their majors and disciplines. An extreme way is to design a discipline-based criterion of performance evaluation for each faculty member. In this case, universities would be caught in a predicament that performance evaluation couldn't be conducted for too many criteria, which would seriously impact the efficiency of university management.

(3) Covertness. Teaching activity, taken place in different time and space, is composed of several processes, such as teaching plan, implementation, teaching control and feedback, etc. Some substantial input related to the effectiveness of 
teaching activity cannot be observed. From a management perspective, there's information asymmetry between administrators and faculty about the time and energy invested in teaching activities. Consequently, faculty possess the chance to select strategic behavior and information advantages concerning the preparation, implementation and management of teaching activities, which objectively decides the limitation of external management model, like processbased management control. Obviously, for lack of internal motivation and faculty members' self-management, university administration and management would be confronted with the challenge of effectiveness.

\section{ANALYSIS ON INSTITUTIONAL REASONS FOR FACULTY MEMBERS' STRATEGIC BEHAVIOR}

According to Contingency Theory, suitable institutional arrangement and management model are objectively required to adapt to faculty's job attributes of teaching and research. So if faculty members' strategic behavior is brought into the framework of administrative governance, it is not hard for us to discover the institutional causes behind that. Public administration is a management model consistent with bureaucracy. Max Weber wrote that the modern bureaucratic organization relies on the following principles: a rigid division of labor, clear hierarchy, responsibility and accountability, uniform and plentiful rules and regulations, impersonal authority, recruitment based on hierarchy and qualification, and administrative efficiency [6]. The typical characteristic of bureaucratic system in public administration is to achieve the efficiency of organization by utilizing rigid rules and regulations to restrain the randomness of its members [7].

\section{A. Effect of Public Administration Thoughts and Culture on Faculty Members' Strategic Behavior}

Generally speaking, public administration in Chinese universities is the direct result of institutional design, involving the value-related content, such as administration thoughts and culture. Overall, administrative governance in Chinese universities can be divided into two dimensions: national-level university administration and university's internal administration. The latter is subject to the former, and is a natural extension and inevitable result of it. In the public administration model, the national-level university governance is mainly utilizing the following measures to realize its administration and fulfill the institutional arrangement: appointment of chief administrators in universities, resource investment, arrangement of mandatory tasks and evaluation. Guided by this model, bureaucratic organization naturally becomes the main model of work design and organizational structure design in universities. Its typical feature is to allocate resources by its internal administrative authority, which will give rise to the 'bureaucratic' thoughts and behavior, and develop the administrative culture in conformance with university's administration model. The thought of public administration tends to utilize the administrative measures to achieve the high efficiency of organization by establishing clear goals, well-defined standards, well-organized procedures and accountability [8]. It follows that the internal governance of university is equated to national-level university administrative governance. For a long time, influenced and restrained by public administrative model and culture, there must be numerous familiar Chinese university phenomena emerging. For instance, proceeding from formulating goals of university development, with the measure of quantitative and assessable indicator system, different management objects are assessed against a uniform criterion to satisfy the demand of high efficiency, neglecting the basic rules of teaching and research, regardless of subjects and disciplines, and overlooking similarities and differences of teaching and research. Under the guidance of such administrative thoughts and culture, for university administrators, whether or not the development goals formulated by the nation can be accomplished is the standard to judge them; for faculty members, whether or not the targets set by the university can be fulfilled is their evaluating standard. As a way of organizational management, public administration covers administrative thoughts, culture, policy orientation, management model, etc. At present, the university governance and management model in Chinese universities are still administration-oriented and the strong administrative flavor would necessarily exert influence on faculty's research and teaching behavior.

\section{B. Effect of Quantitative Assessment and Economic Incentive on Faculty Members' Strategic Behavior}

The administrative appointment and tenure of university administrators decide their rational behavior, and that is to meet the realistic demands of educational administration department. Consequently, unrealistic pursuit of instantly effective 'ranking and rating' must be their inevitable choice to maximize their self-interest. The short-term behavior of university administrators reflected in various institutional arrangement and incentives, entices faculty members to change their leading behavior, which means that the academic rigor and holiness give way to materialism and instrumental rationality. Under the public administration model, government as the administrator and investor of higher education manages the university mainly by means of appointing its president and allocating educational resources, which follows the two problems that is how to evaluate universities' operating efficiency and what kind of standards should be employed to allocate educational financial investment.

Research and talents nurturing are two primary activities in universities. By contrast, scientific research has a natural advantage for it can be easily measured and evaluated, while talents nurturing is confronted with the challenge that it is unable to be measured. Scientific research is quantifiable, easy to be taken as the evaluation tool to manage and assess the level of the administrator and university running, and then brought into the evaluation system of examining university's effectiveness, which determines the relevant support from the nation. In the competitive market where national investment in educational resources is limited, influenced by government's preference of research results, for the purpose of gaining enough resources, universities rationally choose to internalize government's emphasis and demands of scientific research, give priority to faculty's research activities, allocate the higher 
proportion to research in the case of professional title promotion and monetary reward allocation, and motivate faculty to invest more time and energy in research.

Faculty members in universities must undertake both teaching and research work, who are the integration of researchers, educators and administrators [9]. With limited time and energy, they will make a decision on how to allocate time and energy to teaching and research. According to the theory of comparative advantage in economics, this decision depends on their own comparative advantages. Only based on this can allocation of resources be beneficial to the improvement of social welfare. Nevertheless, faculty members are not 'saints', but 'rational economic men'. Whether to invest time in research or teaching is not only determined by comparative advantages, but also the cost-benefit analysis. Although teaching and research, in essence, are interdependent, mutually conditional and highly relevant, under the administrative mode of laying more stress on research than teaching, their relation are artificially divided into different work content with different personal economic benefit and social value by the design of administration system, developing into two dimensions: (1) as for the university, research becomes the key factor to decide the behavior of secondary units (schools); (2) as for university faculty, more emphasis is put on research, while passive attitude towards teaching is taken, and even some professors refuse to give lectures to undergraduates.

In recent years, along with the increasing national investment in education, the financial situation of universities is obviously improved, thereby weakening the budget constraint. Under the research-leading administration mode, universities enhance the investment in research and a variety of incentives including project application, paper publication and awarded research results are formed. The organization goal conveyed by these institutional arrangements to faculty members enables them to attach more importance to research, thereby promoting the progress of university's research work. However, the negative effects it follows cannot be ignored. For one thing, with the temptation of economic benefit that research brings, many faculty members devote their full time and energy to scientific research, reducing investment in teaching. For another, for the sake of generating research results as soon as possible, individual faculty members ignore the fundamental spirit of scientific research, heedless of research morals; they complete their compulsory research tasks by means of plagiarism and fraud. As academic trash and bubble continually arise, some faculty members are corrupted, discarding the pursuit of truth and research spirit of innovation. The trend of utilitarianism becomes evident. What's worse, since faculty's research concerns the interest of university, when academic misconduct was found, many universities would reduce major troubles to minor ones and minor ones to nothing to protect their reputation. Therefore, the academic misconduct of individual faculty members cannot be handled and published instantly. Such indulgence enables the individual incidents to evolve into the group behavior. If this phenomenon cannot be controlled in time, it will turn into a public hazard, which will seriously aggravate the academic environment.

\section{GOVERnANCE OF UNIVERSITY FACULTY StRATEGIC BEHAVIOR}

The realization of university's social function cannot do without faculty members' teaching and research. Such different job attributes objectively require that the university should follow the basic law of teaching and research and conduct different administrative system designs. As a matter of fact, university faculty's strategic behavior is irresponsible and immoral, which is the rational choice of 'rational social being' in the university's management system. What's more, the university-level system design is closely related to national-level administrative model. That is to say, based on public administration, university's management model will surely lead to the emphasis on research. Consequently, teaching falls into the 'secondary job', becoming next-best alternative for university faculty. Accordingly, negligence in undergraduate teaching becomes a natural corollary. Furthermore, to evaluate research work by rigid indicators and standards will bring about the lost of the research's life and social significance, enabling research to evolve into a tool for rational individuals to make a living and gain resources. It highlights the economic significance, ignores and underestimates the 'holiness' of research work itself. Research losing the deserved dignity and respect, academic fraud then also becomes a natural corollary. At present, such kind of strategic behavior is individual phenomenon in faculty group, yet it will exert a profound influence on long-term development of our nation, which should be stressed, governed and regulated.

\section{A. Straighten out the Relationship between Government and University, and Define Their Behavior Boundaries}

University is an organization within the system of social division of labor. Social development is influencing university's progress. The foundation and premise of university's sustainable development is to fulfill its social duties and responsibilities. In the whole society-university ecosystem, the establishment of government-university relationship is crucial. In China, such relationship can be regarded as relationship of administrative subordination. In view of it, 'de-administration' is the key to straightening out the relationship between government and university. The connotation of 'de-administration' is that university should free itself from the constraint of government power system, and build its own corporate governance, which is the basic requirement of modern university system [10]. In the system of social division of labor, university with four functions, namely nurturing the talents, generating knowledge, serving society and inheriting \& passing on culture is a typically quasi-public product. First, government is the investor of a university, providing financial support to university's development. Then, as the competent authority of administration, government ought to manage the university from the macroscopic level by legislation, financial allocation, planning, information service and policy, rendering the university being a truly legal entity which can have independent rights of running school. Accordingly, to be the independent body of running school, university should be entitled with the following duties: formulate university regulations according to the basic law of teaching and research, 
found a valid internal governance structure, conduct various work based on the demands for research and teaching from social development, provide the superior intellectual service for nurturing talents, generating knowledge, serving the society, inheriting and passing on culture.

\section{B. Understand the Relationship between Teaching and Research, and Develop Their Constructive Interaction}

Knowledge is the common element involved in various activities in university educational system. It is generated through research, preserved and refined via academic work, disseminated by teaching and service [11]. It shows that research not only aims to generate knowledge, but also disseminate knowledge. The value of research is ultimately embodied in teaching, which examines the value of knowledge as well. Teaching activity not just expands the research fields, but promotes the value of research activity. It is proven that research and teaching exert equivalent effect and role in realization of university's function. They are mutually beneficial and supportive, and then should be given equivalent treatment. Stressing too much on one side is undesirable for university to develop healthily. For this reason, concerning system design, university should be fully conscious of the above-mentioned relationship between research and teaching. In order to make the best use of research results in teaching, enhance the quality of talents nurturing, and to develop the constructive interaction between teaching and research, a range of measures can be taken, such as requiring professors to deliver lectures to undergraduates in performance assessment, encouraging faculty members to involve undergraduates in their research programs by means of institutional arrangement and financial support, etc.

\section{Establish a Valid Classified Evaluation System to Provide More Options for Faculty}

University faculty plays a crucial role in academic research. Developed for years, comparatively sophisticated evaluation system and indicator system have been formed [12]. However, the establishment of these systems is based more upon the need of university's public administration; and human factors are ignored. The differences of faculty members' capacity, interest, disciplines and majors don't get the deserved attention. The pursuit of administrative efficiency far exceeds that of justice and humanism. The uniform design of evaluation indicators, combined with the undesirable culture in the process of evaluation, together create vulgar culture of university's evaluation. The widespread existence of this culture not just corrupts the professional ethics of faculty members, but put more occupational stress on them, thereby worsening the burnout effect in faculty group. For this reason, the evaluation indicators should be set following the fact that the capacities vary from one person to another, and classified by diverse disciplines, majors, research and teaching. In a comparatively fair indicator system, faculty members can choose relatively advantaged work according to their own interest, preference and capacity structure. They can focus more on either teaching or research, and also strike a balance between them. In this case, faculty members can make full use of their advantages and specialties so as to contribute more to teaching and research in the university.

\section{Enhance the Self-discipline Mechanism of University Faculty, to Create a Favorable Atmosphere of Self- restraint}

University, as a process-oriented evolving system, needs not only the flexible control system - incentive mechanism that conducts the goals of university to individuals and stimulates their self-management, but also the rigid control system-constraint mechanism that regulates individual behavior to guarantee the goals of university can be reached effectively [13]. The job attributes of research and teaching decide the significance of faculty's self-discipline. Actually, in the same institutional environment, there are still numerous faculty members who are enthusiastic about undergraduate teaching, immersing themselves in nurturing talents; meanwhile, there are also many faculty members who devote themselves to research, regardless of various kinds of administrative evaluation indicators. Their attitude and behavior are dramatically opposed to the strategic behavior of individual faculty members mentioned above. The stories of these prominent faculty members and researchers reflect their high-level sense of responsibility, and manifest that selfdiscipline mechanism exerts influence on their behavior and motives. At present, within the whole university management system, the external heteronomy is comparatively mature, while the construction and effect of self-discipline mechanism have been ignored. During the process from professionals to faculty members, their professional ethics education is relatively insufficient. The lack of self-discipline mechanism necessarily leads to their different perception of teaching and research, thus giving rise to above-mentioned irrational behavior. Therefore, equal importance should be attached to the construction of both heteronomy and self-discipline mechanism; and the education of professional ethics and skills should be enhanced simultaneously.

\section{CONCLUSION}

It is obvious that in the university's institutional and management system which is relied mainly on bureaucracy and public administration, government's management of university is liable to standardized and quantitative management mode. Moreover, some attributes of research accord with the requirement of quantitative management mode, thereby research being the first choice for higher education investors and administrators to evaluate the university. In a highly competitive environment, or with scarce educational resources, to scramble for more educational resources, the administrators of university are bound to adopt the same management mode. Thus in the whole evaluation system of the university, the basic pattern of research prior to teaching is formed. Influenced by such management mode, faculty members lay much more emphasis on research than teaching, thereby causing the alienation of faculty's behavior, namely, refusal to give lectures to undergraduates, academic dishonesty and data frauds. The strategic behavior of university faculty results from the internal contradictions between administrative governance of university and faculty's teaching \& research activities. Problems and contradictions do not automatically resolve themselves, so some recommendations for governance of university faculty's 
strategic behavior are: straighten out the relationship between government and university, follow the basic rules of teaching $\&$ research activities, stick to people-oriented management, promote the normalization of faculty's behavior via the construction of self-discipline mechanism, and facilitate the benign development of university faculty.

\section{REFERENCES}

[1] Guo, Xiaoli., He, Yunfeng,. \& Zhang, Li. (2016). University Teacher: Interpretation as an Academic Profession. Theory and Practice of Education. Vol.36. No.1. pp.41-44.

[2] Jia, Yongtang. (2012). The Impact of the Faculty Evaluation System on Their Role Behavior. Journal of Higher Education. Vol.33. No.12. pp.57-62.

[3] President Hu Jintao's speech in celebrating convention of the 100th anniversary of establishing Tsinghua University.

[4] Zhong, Binglin., Liu, Li. (2012). The Current Situation, Difficulties and Response of Faculty Development in China. Journal of National Academy of Education Administration. No.9. pp.50-54.

[5] Wu, Daguang. (2010). Complexities and Values of University Differentiation. Educational Research. No.12. pp.20-23.

[6] Yu, Xianyang. (2001). Organizational Sociology. Beijing: China Renmin University Press.
[7] Ding, Husheng. (2012). The Structural Elements and Forms of University Organizations. Journal of Northwest Normal University (Social Sciences). Vol.49. No.6. pp.113-119.

[8] Wu, Hongfu. (2011). The Historical Evolution of Relationship between Teaching and Research in Chinese University. Higher Education Exploration. No.6. pp.98-102.

[9] Liu, Chunhua. (2011). Thought on the Coexistence of Eliminating 'Trend' of Administration and Only 'Respect' Academics: The Necessity and Possibility of Internal Governance of University. Research in Educational Development. No.19. pp. 31-35.

[10] Du, Dengbing., Li, Pengfei., Wang, Junsong., \& Ma, Yahua. (2013). Thought and Suggestion on Reform of Science \& Technology Evaluation System in Chinese University. China Higher Education. No.1. pp.16-19.

[11] Qian, Yingyi. (2015). University Governance: American, European, Chinese. Tsinghua Journal of Education. Vol.36. No.5. pp.1-12.

[12] Li, Liguo. (2016). Transformation and Modernization of the University Governance. University Education Science. No.1. pp.24-40.

[13] Xu, Jingjun. (2003). Exploring a New Theory: Self-Organization Theory of the Firm. Nankai Business Review. No.3. pp.37-42. 